\title{
A agricultura familiar no cenário da produção de florestas energéticas
}

\author{
Family farming in the scenario of production of energy forests \\ Jordana Georgin', Flávio Laureano², Jorge Farias³, Luís Henrique Laner Rodrigues ${ }^{4}$ \\ ' Engenheira ambiental, Universidade Federal de Santa Maria \\ 2,34 Engenheiro ambiental, Universidade Federal de Santa Maria
}

\section{Resumo}

O objetivo do estudo foi analisar a produção de florestas energéticas de eucaliptos como alternativa econômica na agricultura familiar da região de Espumoso - RS, com o uso de recursos do Plano Safra 2012/2013. A metodologia usada para o estudo de mercado, levantamento de custos de manutenção e implantação e preços foi à aplicação de perguntas abertas via telefone, e-mail e in loco para profissionais, instituições e empresas do setor florestal da região. Para a análise da viabilidade econômica do mercado energético da região foi criado um cenário de 1 hectare, destinado a produção de lenha para energia com corte aos 5 anos de idade, venda do mato em pé, com preço e incremento médio de, respectivamente, $\mathrm{R} \$ 50,00 \mathrm{~m}^{3}$ e $250 \mathrm{~m}^{3} / \mathrm{ha}$ /ano. Os custos médios de implantação e manutenção são de $\mathrm{R} \$ 2905,50$ e a avaliação econômica do cenário foi calculada através do VPL, TIR e B/C. O cenário foi considerado viável, com o VPL positivo, a TIR maior que a taxa mínima de atratividade e a B/C maior que 1. Com este estudo conclui-se que o investimento em implantação de plantios de eucaliptos na região de Espumoso é uma ótima opção para aumentar a rentabilidade financeira proporcionada pela atividade rural.

Palavras-chaves: Agricultura familiar, Mercado de lenha, Rentabilidade e eucaliptos.

\begin{abstract}
The aim of this study is to analyze the production of energetic forests of eucalyptus as an alternative economic in family farming region of Espumoso - RS, using resources from Harvest Plan 2012/2013. The methodology used for market research, survey implementation and maintenance cost and price was the application of open questions via phone, email and on-site for professionals, institutions and companies in the forest sector in the region. For the analysis of the economic viability of the energy market in the region has created a scenario of 1 hectare to produce wood for energy cut at 5 years of age, sale of forest standing, price and average increase of respectively $\mathrm{R} \$ 50.00 \mathrm{~m}^{3}$ and $250 \mathrm{~m}^{3} / \mathrm{h}$ /year. The average costs of deployment and maintenance are $\mathrm{R} \$ 2,905.50$ and economic evaluation of the scenario was calculated using the NPV, IRR and B/C. The scenario was considered viable, with positive NPV, IRR greater than the minimum rate of attractiveness and $\mathrm{B} / \mathrm{C}$ greater than 1 . With this study we can conclude that investment in deployment of eucalyptus plantations in the region of Espumoso is a great option to increase the financial return provided by rural activity.
\end{abstract}

Keywords: Family Farming, Firewood Market, Profitability 


\section{INTRODUÇÃO}

A expansão e modernização da agropecuária brasileira, apesar de contribuir significativamente para o aumento da produção e da produtividade agrícola e pecuária, provocaram grande redução da cobertura florestal e diminuição da oferta de produtos florestais, causando alterações no funcionamento dos ecossistemas naturais, especialmente no que se refere ao desequilíbrio no regime das águas e do clima.

A sociedade brasileira necessita cada vez mais de soluções que permitam a expansão da produção agrícola e de produtos florestais, associados à preservação ambiental, além de alternativas de emprego e renda, particularmente para os pequenos e médios produtores rurais (RODIGHERI, 1997).

A cobertura florestal em áreas rurais traz consigo benefícios diretos e indiretos, tais como proteção do solo contra erosão, aumento da retenção da água no solo, geração de empregos e melhoria da distribuição de renda, contribuindo, assim, para uma melhoria de ordem social e econômica dos produtores e de suas famílias.

O Brasil é privilegiado por ter ampla cobertura florestal, rica em biodiversidade, embora, muitas vezes, tal cobertura seja considerada impeditiva ao desenvolvimento do país. Dessa forma, o modelo de ocupação utilizado, em diferentes regiões do país, tem provocado à substituição da cobertura florestal por atividades sócio-econômicas (agrícolas, pecuárias, mineração, entre outras) não sustentáveis.

Para reverter esse histórico de ocupação, há necessidade de promover políticas públicas capazes de aperfeiçoar o uso da terra, além de incentivar os plantios florestais, em áreas alteradas, destacandose os sistemas agroflorestais.

Ao longo dos anos os conceitos referentes ao desenvolvimento sustentável da agricultura familiar foram se consolidando e sendo incorporados às políticas públicas brasileiras. Desde o final dos anos 90 e início do atual século um conjunto de políticas públicas foram sendo formuladas e implementadas pelo Governo Federal no sentido de fomentar e desenvolver os agricultores de perfil familiar, não apenas num sentido de ações subsidiadas, mas passando a definir uma agenda estratégica diferenciada que reconhece nesse público um potencial de geração de renda, emprego, produção e dinamismo econômico e social.

Segundo a Embrapa (2004), a inserção no mercado ou no processo de desenvolvimento depende de tecnologia e condições políticas institucionais, representadas por acesso a crédito, informações organizadas, canais de comercialização, transporte, energia, etc. Este último conjunto de fatores normalmente tem sido a principal limitante do desenvolvimento. Embora haja um esforço importante do Governo Federal com programas como o Pronaf, programas estaduais de assistência técnica e associativismo há um imenso desafio a vencer.

Contudo o presente estudo teve como objetivo, analisar a produção de florestas energéticas como alternativa econômica na agricultura familiar da região de Espumoso/RS, com o uso de recursos do Plano Safra 2012/2013.

\section{MATERIAL E MÉTODOS}

O município de Espumoso está localizado na região Centro-norte do Rio Grande do Sul, mostrado no mapa abaixo e possui classificação climática tipo Cfa (úmido em todas as estações do ano, verão quente e moderadamente quente). Apresenta Coordenadas geográficas da sede municipal: $29^{\circ}$ 02'41" de Latitude Sul e 53 03'44' de Longitude. Altitude: 365 metros. Sua vegetação se apresenta como de pequeno porte, extinção quase total das matas nativas, existindo mini redutos de vegetação de grande porte. A Zona Urbana conta com 11.525 habitantes e a Zona Rural 4905 habitantes, População Total- 16.430 habitantes (Fonte IBGE, 2010), A superfície do município é de 823,90 Km². Área urbana do município: $12 \mathrm{Km}^{2}$, Área rural do município: $811,90 \mathrm{Km}^{2}$.

A área de estudo abrange os municípios de: Tapera, Lagoa dos Três Cantos, Não-me-toque, Victor Graeff, Selbach, Ibirubá, Alto Alegre, Campos Borges, Jacuizinho, Salto do Jacuí, Mormaço e Soledade.

O motivo da escolha de Espumoso foi pela sua localização, centralizada em relação a estes municípios e pelo histórico da região em que a maioria destes municípios pertenciam a Espumoso antes de se emanciparem. 
A agricultura é fator predominante na economia do município e da região, a qual o projeta dentro do Estado e no cenário nacional. Os produtos mais significativos são: soja, trigo e milho destacando-se também a bacia leiteira. Também destacam-se a pecuária de bovinocultura de corte, a produção de outros grãos e a produção de Citrus relacionados a hortifrutigranjeiros, que assim como na área do leite vendem a maior parte da sua produção para as sociedades agrícolas das próprias cidades, empresas e agroindústrias do ramo.

A produção florestal na região se refere basicamente à produção de lenha e toras, com a maioria da produção oriunda da silvicultura. Além destes principais produtos, a região apresenta também outras formas de produção florestal como a produção de carvão vegetal nas cidades de Espumoso, Lagoa dos Três Cantos, Victor Graeff, Jacuizinho, Soledade e Mormaço, na produção de Erva-mate com destaque para as cidades de Soledade, Mormaço e Victor Graeff e também na produção de madeira de Pinheiro brasileiro nativo (Araucaria angustifólia) e seus derivados alimentícios, o pinhão.

Após o levantamento dos valores de custos de implantação e manutenção de povoamentos de eucalipto para lenha, produção média, valores pagos pela matéria - prima, foi elaborado um cenário para avaliar a viabilidade dessa atividade considerando a taxa de juros do Pronaf Florestal Plano Safra 2012/2013.

Para a análise econômica dos cenários foram utilizados critérios de avaliação, escolhidos entre os principais e mais utilizados em trabalhos sobre análise econômica em projetos florestais. São eles: Valor Presente Líquido (VPL), Taxa Interna de Retorno (TIR) e Razão Benefício Custo (B/C). Os cálculos foram realizados a partir dos dados coletados e organizados em planilhas do Microsoft Office Excel 2010.

\section{RESULTADOS E DISCUSSÃO}

Segundo a Cotriel, os custos médios de implantação e manutenção de reflorestamentos com Eucalipto seguem conforme o preço de mercado dos insumos e serviços da região. Os dados com os respectivos valores seguem abaixo na Tabela 1.

Tabela 1 - Custos médios de implantação e manutenção de reflorestamentos de Eucalipto na cidade de Espumoso e região.

\begin{tabular}{c|c|c}
\hline & ATIVIDADES & VALORES (R\$) \\
\hline \multirow{4}{*}{ IMPLANTAÇÃo } & Preparo da área & 1000 \\
\cline { 2 - 3 } & Mão de obra* & 350 \\
\cline { 2 - 3 } & Adubo (calcário e químico) & 400 \\
\cline { 2 - 3 } & Combate às formigas & 100 \\
\cline { 2 - 3 } & Mudas (1667 x R\$0,25) & 416,75 \\
\hline \multirow{3}{*}{ MANUTENÇÃO } & Mão de obra* & 400 \\
\cline { 2 - 3 } & Mudas replantio (10\% de perda $=167 \times \mathrm{R} \$ 0,25)$ & 200 \\
\cline { 2 - 3 } & Adubo de cobertura & $\mathbf{2 . 9 0 8 , 5 0}$ \\
\hline
\end{tabular}

Fonte: Cotriel, 2011.

*Mão de obra relativa aos serviços de capina, roçada, aplicação dos insumos manual e com utilização de maquinário. 
Os custos foram determinados a partir de plantios com espaçamento de $3 \times 2$, que é o mais utilizado na região tanto para lenha quanto para serraria, para um total de 1667 mudas e perdas de $10 \%$. O preço médio pago pela madeira para energia segue abaixo na Tabela 2.

Tabela 2 - Valores médios pagos por metro cúbico de madeira de lenha para energia e de toras para serrarias (2011).

\begin{tabular}{c|c|c}
\hline Matéria - prima & Valor $\left(\mathbf{R} \$ / \mathbf{m}^{3}\right)$ & Condição \\
\hline LENHA & 25 & Mato em pé \\
\hline
\end{tabular}

Considerando que esse preço é pago pelo mato em pé com idade média de 5 anos para lenha e leva-se em conta o deslocamento do plantio até o pátio da empresa a qual a mesma realizada o processo de derrubada e transporte.

A produção de lenha para energia no município de Espumoso e região é toda voltada para alimentar as fornalhas para a secagem de grãos de culturas anuais como soja e milho, salvam-se poucas as quantidades para consumo próprio. Os dados relativos à lenha foram obtidos a partir da colaboração da administração da Cooperativa Tritícola de Espumoso Ltda (Cotriel) onde foi fornecido o consumo de lenha para o Plano Safra 2010 - 2011 da matriz, localizada no próprio município, e de todas as filiais que se estendem nos municípios de Campos Borges, Alto Alegre, Salto do Jacuí, Jacuizinho, Estrela Velha, Arroio do Tigre, Sobradinho e Pantano Grande, além das filias no interior do município. Abaixo segue a tabela com o consumo de lenha da matriz e de suas filiais $\mathrm{em}^{3}$ anual e mensal.

Tabela 3 - Consumo de lenha no município de Espumoso e região relativo ao Plano Safra 2010 - 2011.

\begin{tabular}{c|c|c|c}
\hline Empresa & Município/localidade & ${\text { Consumo } \mathbf{~ m}^{\mathbf{3}} / \mathbf{m e ̂ s}}^{\text {Consumo } \mathbf{~ m}^{\mathbf{3}} / \mathbf{a n o}}$ \\
\hline Cotriel & Espumoso/sede & 115,3 & 1384 \\
\hline Cotriel & Espumoso/Depósito & 29,8 & 358 \\
\hline Cotriel & $\begin{array}{c}\text { Espumoso/Pontão do } \\
\text { Butiá }\end{array}$ & 33,5 & 402 \\
\hline Cotriel & $\begin{array}{c}\text { Espumoso/Serra dos } \\
\text { Engenhos }\end{array}$ & 30,8 & 370 \\
\hline Cotriel & $\begin{array}{c}\text { Espumoso/Capão do } \\
\text { Valo }\end{array}$ & 33,3 & 399 \\
\hline Cotriel & Salto do Jacuí & 31,4 & 377 \\
\hline Cotriel & Campos Borges & 59,8 & 718 \\
\hline Cotriel & Alto Alegre & 33,5 & 402 \\
\hline Cotriel & Pantano Grande & 99,1 & 1190 \\
\hline Cotriel & Estrela Velha & 133,3 & 1600 \\
\hline Cotriel & Arroio do Tigre & 80 & 960 \\
\hline Cotriel & Sobradinho & 13,6 & 163 \\
\hline TOTAL & - & $\mathbf{6 9 3 , 6} \mathbf{~ m}^{\mathbf{3}} / \mathbf{m e ̂ s}$ & $\mathbf{8 3 2 3} \mathbf{~ m}^{\mathbf{3}} / \mathbf{a n o}$ \\
\hline
\end{tabular}

Fonte: Cooperativa Tritícola de Espumoso Ltda, 2011.

Segundo o IBGE (2011), somente na cidade de Espumoso entre as culturas mais cultivadas, soja e milho, apresentaram respectivamente, uma produção de 143.100 e 11.700 toneladas. Segundo Junior et al (2006) para cada tonelada de soja e de milho produzida, deve-se ter 0,17 e $0,25 \mathrm{~m}^{3}$ de madeira de eucalipto para secá-las. Assim, para a região de estudo, necessita-se de $24.327 \mathrm{~m}^{3}$ para secar soja e $2.925 \mathrm{~m}^{3}$ para secar trigo. Considerando um incremento médio de povoamento de eucalipto na região de $50 \mathrm{~m}^{3} /$ ha/ano e corte final aos 5 anos, a área de eucalipto necessária para secagem de soja é 97,3 hectares e de trigo é 11,7 hectares.

Segundo a Cotriel, a matéria - prima para os secadores é oriunda de produtores associados, 
que atingem uma área de cerca de 46 hectares de Eucalipto por ano, com o corte feito aos 5 anos de idade. O restante é comprado de empresas de reflorestamento localizadas no município de Pantano Grande, localizado a mais de $200 \mathrm{~km}$ de Espumoso. Cabe ressaltar que essa estimativa é de apenas para os secadores de soja e milho, não incluindo outras culturas como trigo e aveia, que não foram incluídas nos cálculos devido à dificuldade de fornecimento de dados. A Cotriel também engloba serviços referentes à bacia leiteira, transformação de carne, lacticínios, moinhos de farinha e panificadoras que alimentam seus mercados.

Ainda na região existem outras grandes empresas, entre privadas e associações, que consomem lenha para energia: Cotrisoja, Cotribá, Cotrisol, Estratégia Agrícola, Agro Bortolan, Capaz, Cepasa. Além disso, a produção é dividida com serrarias onde aproveitam as toras maiores para outras finalidades.

Considerando estes dados fica visível a falta de matéria - prima para energia para a Cotriel e para as outras empresas da cidade e da região, quando a demanda supera a oferta. Isso mostra que há mercado para energia na região e que a associação entre a Cotriel com os produtores pode ser aumentada e as outras empresas podem seguir este mesmo caminho. Esta relação entre empresas e produtores deve seguir como um associativismo florestal trazendo benefícios aos dois lados. Assim as empresas não teriam problemas com a busca de matéria - prima em outra região e a produtora contaria com apoio técnico e financeiro para implantação, manutenção e extração dos povoamentos, além da venda garantida a estas empresas.

Diante dessa situação o cenário para povoamentos de eucalipto voltado à energia, usando os valores médios de custos de produção e preço por $\mathrm{m}^{3}$ de matéria-prima está exposto na tabela 4 .

Tabela 4 - Valores do Cenário.

\begin{tabular}{l|l}
\hline Mecanismos de financiamento & PRONAF Floresta \\
\hline Taxa de juros & $1 \%$ a.a. \\
\hline Modalidade & Investimento \\
\hline Crédito & $\mathrm{R} \$ 25.000,00$ \\
\hline Prazo de pagamento & Até 20 anos \\
\hline Carência & Até 12 anos \\
\hline Área do projeto & 1 hectare \\
\hline Espaçamento & $3 \times 2$ \\
\hline Incremento Médio Anual (IMA) & $50 \mathrm{~m}^{3} / \mathrm{ha} /$ ano \\
\hline Métodos de avaliação & VPL, TIR e B/C \\
\hline Condição de venda & Mato em pé \\
\hline
\end{tabular}

$\mathrm{Na}$ avaliação econômica do cenário foi levada em conta os custos, preços e produção média da região para a realização a partir dos métodos de avaliação. Os dados estão apresentados na tabela 5.

Tabela 5 - Dados da produtividade e renda por hectare.

\begin{tabular}{|c|c|c|c|c|c|}
\hline Área (ha) & $\begin{array}{c}\text { Valor } \\
\left(\mathrm{R} \$ / \mathrm{m}^{3}\right)\end{array}$ & $\begin{array}{c}\text { Produção } \\
\left(\mathbf{m}^{3} / \mathrm{ha}\right)\end{array}$ & $\begin{array}{c}\text { Receita Bruta } \\
\text { (R\$/ha) }\end{array}$ & $\begin{array}{l}\text { Custos } \\
\text { (R\$/ha) }\end{array}$ & $\begin{array}{c}\text { Receita } \\
\text { Líquida(R } \$ / \text { ha })\end{array}$ \\
\hline 1 & 25 & 250 & 6.250 & $2.908,50$ & $3.341,50$ \\
\hline
\end{tabular}

O VPL foi positivo, a TIR foi maior que a taxa mínima de atratividade e a relação Benefício Custo é maior que 1 , mostrando que a cada $R \$ 1,00$ investido haverá retono de $R \$ 1,15$, mostrando a viabilidade econômica da produção de florestas energéticas na região de Espumoso. Os resultados dos métodos de avaliação estão expostos na tabela 6 .

Torna-se importante ressaltar que os valores utilizados são valores médios, mesmo assim mostrando que o investimento em produção de lenha de eucalipto mostrou-se, de modo geral, viável economicamente. Deve-se considerar também que terras normalmente utilizadas para reflorestamento 
são consideravelmente mais baratas, geralmente inferiores ao preço médio de US\$ 500,00/ha (IBGE, 2010). Assim considerando que em dadas propriedades da região podem existir porções de terra com preços abaixo desse valor, geralmente áreas com declividade acentuada que se tornam ociosas devido à impossibilidade do cultivo de grãos, o plantio de Eucalipto se torna justificável se apresentando como nova fonte de renda.

Tabela 6 - Resultados dos métodos de avaliação econômica do Cenário.

\begin{tabular}{c|c|c}
\hline VPL & TIR & B/C \\
\hline 3038,16 & $17 \%$ & 2,15 \\
\hline
\end{tabular}

\section{CONCLUSÃO}

A região de Espumoso tem sua economia no meio rural voltada basicamente para a agricultura (soja, milho e trigo). Nesse contexto, a produção de florestas energéticas para a secagem de grãos torna-se uma atividade rentável economicamente devido à necessidade de suprir a demanda desse mercado local. Diante disso, o pequeno produtor rural pode inserir-se na atividade, diversificando sua produção evitando a dependência exclusiva de um mercado tão oscilante com o de grãos, gerando renda e empregos no contexto da agricultura familiar regional.

\section{REFERÊNCIAS}

AFONSO JÚNIOR, P.C.; OLIVEIRA FILHO, D. Estudo da viabilidade econômica de produção de lenha de eucalipto (Eucalyptus sp.) em área de lavoura para secagem de produtos agrícolas. In: Eng. Agríc., Jaboticabal, v.26, n.1, p.28-35, jan./abr. 2006.

COTRIEL, 2011. Cooperativa Tritícola de Espumoso Ltda. Espumoso, RS.

EMBRAPA - Empresa Brasileira de Pesquisa Agropecuária. Disponível em: < http://www.embrapa.br/ imprensa/artigos/2002/artigo.2004-12-07.2590963189/>. Acesso: 01/11/2012

IBGE. Instituto Brasileiro de Geografia e Estatística. Censo Agropecuário 2011.

IBGE. Instituto Brasileiro de Geografia e Estatística. Produção da Extração Vegetal e da Silvicultura. 2010.

RODIGHERI, H. R. Rentabilidade econômica comparativa entre plantios florestais e sistemas agroflorestais com erva-mate, eucalipto e pinus e as culturas do feijão, milho, soja e trigo. Colombo:EMBRAPA-CNPF, 1997. 36p. (Circular técnica, n.26). 